\title{
Comparison of AERONET and SKYRAD4.2 inversion products retrieved from a Cimel CE318 sunphotometer
}

\author{
V. Estellés ${ }^{1,2}$, M. Campanelli ${ }^{3}$, M. P. Utrillas ${ }^{1}$, F. Expósito ${ }^{2}$, and J. A. Martínez-Lozano ${ }^{1}$ \\ ${ }^{1}$ Dept. Física de la Terra i Termodinàmica, Universitat de València, C/Dr. Moliner 50, 46100 Burjassot, Spain \\ ${ }^{2}$ Dept. Física Fundamental y Experimental, Electrónica y Sistemas, Universidad de La Laguna, Avda. Astrofísico Francisco \\ Sánchez s/n, 38209 San Cristóbal de La Laguna, Santa Cruz de Tenerife, Spain \\ ${ }^{3}$ Institute of Atmospheric Sciences and Climate, Italian National Research Council, Via Fosso del Cavaliere, \\ Roma Tor Vergata, Italy
}

Correspondence to: V. Estellés (victor.estelles@uv.es)

Received: 30 September 2011 - Published in Atmos. Meas. Tech. Discuss.: 18 November 2011 Revised: 10 February 2012 - Accepted: 12 February 2012 - Published: 13 March 2012

\begin{abstract}
SKYNET is an international research network of ground based sky - sunphotometers for the observation and monitoring of columnar aerosol properties. The algorithm developed by SKYNET is called SKYRAD.pack, and it is used on Prede instruments only. In this study, we have modified the SKYRAD.pack software in order to adapt it to Cimel sunphotometers. A one month database of Cimel data obtained at Burjassot (Valencia, Spain) has been processed with this program and the obtained inversion products have been compared with AERONET retrievals. In general, the differences found were consistent with the individual error assessments for both algorithms. Although the aerosol optical depth compared well for any aerosol burden situation (rmsd of 0.002-0.013 for all wavelengths), inversion products such as the single scattering albedo, refractive index and asymmetry parameter compared better for higher turbidity situations. The comparison performed for cases with an aerosol optical depth at $440 \mathrm{~nm}$ over 0.2 showed rms differences of $0.025-0.049$ for single scattering albedo, $0.005-0.034$ for the real part of refractive index, $0.004-0.007$ for the imaginary part of the refractive index and 0.006-0.009 for the asymmetry parameter. With respect to the volume distributions, the comparison also showed a good agreement for high turbidity cases (mainly within the $0.01-7 \mu \mathrm{m}$ interval) although the already known discrepancy in the extremes of the distribution was still found in $40 \%$ of the cases, in spite of eliminating data and instrumental differences present in previous studies.
\end{abstract}

\section{Introduction}

In order to estimate the radiative effect of the atmospheric aerosols in the climate system, it is of the upmost importance to accurately determine their optical and radiative properties in the atmospheric column. These properties are retrieved by applying the sunphotometric and aureole techniques. These techniques consist of inverting sun and sky radiometric measurements, obtained at ground by means of automatic solar radiometers.

In the sunphotometric technique, the aerosol optical depth (AOD) can be inferred from the direct sun irradiance, representing the aerosol extinction, and therefore related to the aerosol burden in the atmospheric column (Estellés et al., 2006). From the combination of sun direct and sky diffuse radiation, further radiative and optical properties can be retrieved (Nakajima et al., 1983, 1996). This can be accomplished by the application of inversion algorithms. The retrieved properties are single scattering albedo, phase function, real and imaginary parts of the refractive index and volume distributions. From the volume distribution and phase function, effective radius and asymmetry parameter can be also determined.

The AOD retrieval from direct sun measurements is a relatively straightforward problem, widely studied in the literature (Estellés et al., 2007a). The current methods are accurate and the comparison between different methodologies compare very well within the estimated uncertainties (Estellés et al., 2006). However, obtaining such a complete 
set of radiative properties in the aureole technique is a difficult task, as the methodology focuses on the solution to an ill-posed problem. The information available in the radiometric data is limited, and it is crucial to adopt plausible assumptions in order to retrieve realistic solutions.

Few different inversion algorithms have been proposed over the years. Nakajima et al. (1996) implemented an original algorithm called SKYRAD. This program was developed to be applied on Prede POM radiometers, and constitutes the starting point for the SKYNET international network. The current network of Prede POM radiometers is mainly spread in Eastern Asia, although it is also present in Europe through the federated European Skynet Radiometers network (ESR) (ESR website, 2011). The SKYNET network currently uses the SKYRAD algorithm version 4.2 (Nakajima et al., 1996). The program is open source code and can be found at the OpenCLASTR website (2011).

In turn, the international Aerosol Robotic Network (AERONET) developed an advanced inversion algorithm (Dubovik and King, 2000) for its application on the Cimel CE318 sunphotometer. The operative network is conducted by NASA in colaboration with other regional federated networks, such as PHOTONS in France or RIMA in Spain. However, the inversion algorithm source code is not publicly available. This implies that independent Cimel CE318 users cannot use this code to invert their own data, neither use it for further algorithm developments.

Few previous studies have addressed the comparison of both network approaches, by comparing the aerosol product retrievals obtained from Cimel CE318 sunphotometers (elaborated by AERONET) and Prede POM radiometers (elaborated by SKYNET) (Sano et al., 2003; Campanelli et al., 2004b; Che et al., 2008). Although differences in the aerosol optical depth were reasonable and within the expected uncertainties, inversion products provided larger differences. The processes behind these differences were difficult to identify and could not be accurately pointed out by these studies. However, it is extremely important to understand these differences, as synergetic studies from both networks would provide a better understanding of the aerosol impact on climate.

In order to better compare both methods by avoiding external instrumental effects (such as calibration, pointing accuracy or temperature dependencies), we have compared the SKYRAD version 4.2 algorithm with the AERONET algorithm by means of using the same Cimel CE318 data and calibration set. Therefore, a pre-processing module was implemented to adapt the Cimel CE318 sunphotometer data to the SKYRAD version 4.2 algorithm, and the method was tested on a 1 month dataset obtained at Burjassot site (Valencia, Spain).

\section{Experimental site and instrumentation}

The Cimel CE318 instrument used in this study is placed at the Burjassot site from the University of Valencia in Eastern Spain (latitude $39.51^{\circ} \mathrm{N}$, longitude $0.42^{\circ} \mathrm{W}, 60 \mathrm{~m}$ a.s.l.). Burjassot is a city of 38400 inhabitants within the Valencian metropolitan area, whose total population is around 1830000 inhabitants. Given its proximity to the principal nucleus of Valencia $(5 \mathrm{~km})$, the measurement station is directly affected by the urban and industrial pollution typical of a metropolitan area. Its closeness to the western coast of the Mediterranean Sea $(10 \mathrm{~km})$ also determines the climatic and meteorologic conditions, with relatively high humidity all year round, mild temperature in winter and high temperature in summer.

A CE318 sunphotometer was deployed in Burjassot site in January 2002, although it only started to operate within AERONET from April 2007 on. The CE318 sunphotometer measures both direct spectral solar irradiance and diffuse sky radiance for almucantar and principal solar planes with a $1.2^{\circ}$ field of view limiting tube. The standard measuring schedule for this instrument broadly consists of direct sun triplets every $15 \mathrm{~min}$, and sky diffuse almucantar or principal plane scenarios every $30 \mathrm{~min}$. This specific unit measured at nominal wavelengths of 340, 380, 440, 500, 675, 870, 936 and $1020 \mathrm{~nm}$. Channels at 340,380 and $936 \mathrm{~nm}$ are only used for sun direct measurements. The sunphotometer currently operates within the Red Ibérica de Medida de Aerosoles (RIMA) and the data are routinely processed by AERONET.

The atmospheric aerosol properties and their air mass dependence at this site were previously examined by Estellés et al. $(2007 a, b)$ using a 4 year long database. Sea breeze is occasionally established at the site, mainly in summertime and under anticyclonic conditions with low pressure gradients, leading to a characteristic pattern of recirculation and ageing of anthropogenic aerosols. During wintertime, clean air masses are occasionally dominant, due to the passage of Atlantic air masses over the Iberian Peninsula. These two meteorological situations lead to two contrasting aerosol escenarios, with maximum turbidity for recirculating local air masses (dominated by anthropogenic aerosols) and minimum turbidity for air masses transported from the northern Atlantic source region (maritime aerosols).

For an average year (Estellés et al., 2007a), the aerosol burden represented by the columnar extinction or aerosol optical depth (AOD) showed an evident seasonal pattern with higher values at summertime (maximum AOD at $500 \mathrm{~nm}$ of 0.38 in July) and minima in wintertime (minimum AOD at $500 \mathrm{~nm}$ of 0.08 in December). The annual mean and median for $500 \mathrm{~nm}$ was 0.22 and 0.19 , with a standard deviation of the sample of 0.13 . For this study we have selected a characteristic 1 month database, obtained in February 2011. During this period, an episode of recirculating air masses with high aerosol burden was clearly identified, isolated by two periods of very clean conditions. 


\section{Calibration}

The sky-sunphotometers need two different calibrations for the sun and sky channels. For the sun direct channel, the calibration is obtained by a transfer from a master instrument. This requires the field instrument to be deployed co-located with a master instrument in a clean site and perform simultaneous measurements of sun direct irradiance during a given time and under certain atmospheric conditions. Then, the calibration for the field instrument is obtained by using the ratio between the master and field instruments.

For the calibration of the sky channel, a source lamp with an integrating sphere must be used. The radiance at the exit port of the integrating sphere is known beforehand (provided by the manufacturer as a traceable calibration). Therefore, the calibration is obtained by measuring the sphere radiance with the Cimel in a darkroom, and converting the digital counts of the instrument to the radiometric magnitude.

Both direct and diffuse calibrations were performed by the RIMA staff at the network calibration site and laboratories, respectively. The calibration at a given time is estimated by linear interpolation between consecutive pre- and postcalibrations. This is the calibration actually employed by AERONET for the processing of this instrument data. These are also the values employed by us in this study. In this way, we can neglect external factors that would be present if we compared two different instruments with their own calibration constants.

\section{Methodology}

\subsection{Aerosol retrieval methodology}

\subsubsection{Inversion algorithms}

Any algorithm for the retrieval of columnar aerosol properties consists of two different components: an accurate forward radiative transfer model, and an optimized mathematical procedure for the inverse transformation of radiance data with a priori constrains (Dubovik and King, 2000). Both AERONET and SKYNET algorithms are based in the same radiative transfer model (Nakajima and Tanaka, 1988), although they differ on the exact implementation of the inversion strategy. In this section we will give an overview of the algorithms, followed by a section with a summary of the different strategies adopted by SKYNET and AERONET and their respective sensitivity and error analysis.

In the radiative transfer model, the direct sun and the sky diffuse radiance components are determined. The monochromatic direct sun irradiance $\mathrm{F}$ can be described from the extinction of the top of atmosphere solar irradiance, as the Beer's law expresses:

$$
F=F_{0} \exp \left(-m_{0} \tau\right)
$$

In this equation, $F_{0}$ is the monochromatic irradiance at the top of the atmosphere measured in $\mathrm{Wm}^{-2} \mathrm{~nm}^{-1}, \tau$ is the total optical depth, and $m_{0}$ is the optical air mass, approached by $m_{0}=1 / \cos \theta_{0}, \theta_{0}$ being the zenith solar angle. If the extraterrestrial irradiance $F_{0}$ is known (related to the instrument calibration factor) and the ground irradiance $F$ is measured, then the aerosol optical depth can be retrieved from this equation after subtraction of the Rayleigh scattering and gas absorption (ozone) optical depths.

In turn, the spectral diffuse sky radiance $E(\Theta)$ can be given at a number of azimuth angles, the latter related to the scattering angles $\Theta$ :

$$
E(\Theta)=F m_{0} \Delta \Omega[\omega \tau P(\Theta)+q(\Theta)]
$$

$\Delta \Omega$ being the solid view angle of the radiometer, $\omega$ the single scattering albedo, $P(\Theta)$ the phase function at scattering angle $\Theta$, and $q(\Theta)$ the multi scattering contribution term. These variables are spectral and in this equation represent the properties of the air and particles ensemble in the whole atmosphere column.

From the direct sun irradiance and the sky diffuse radiance, the relative intensity $R(\Theta)$ is defined as the ratio between the diffuse to direct components:

$R(\Theta)=\frac{E(\Theta)}{F m_{0} \Delta \Omega}=\omega \tau P(\Theta)+q(\Theta) \equiv \beta(\Theta)+q(\Theta)$

where $\beta(\Theta)$ represents the single scattering term, in opposition to the multi scattering term $q(\Theta)$. The ratio $R(\Theta)$ is a magnitude less affected by the interference filter degradation, and can be more accurately determined.

On the other hand, the inversion algorithm can be designed for the retrieval of the spectral optical characteristics of columnar aerosol (i.e. aerosol optical depth, single scattering albedo and phase function), or alternatively, microphysics parameters (Dubovik and King, 2000) such as particle size distribution and complex refractive index. The relation between both sets of aerosol parameters can be found in the following integrals:

$$
\begin{aligned}
& \tau_{\mathrm{a}, \mathrm{ext}}(\lambda)=\frac{2 \pi}{\lambda} \int_{r_{\min }}^{r_{\max }} K_{\mathrm{ext}}(x, \tilde{m}) v(r) d \ln (r) \\
& \beta_{\mathrm{a}}(\Theta)=\frac{2 \pi}{\lambda} \int_{r_{\min }}^{r_{\max }} K(\Theta, x, \tilde{m}) v(r) d \ln (r) .
\end{aligned}
$$

In the integrals, $x$ is the size parameter defined by $2 \pi r / \lambda$, $\tilde{m}$ is the aerosol complex refractive index, $v(r)$ is the columnar aerosol volume distribution and $r_{\min }$ and $r_{\max }$ are the minimum and maximum aerosol radii, respectively. $K_{\text {ext }}(x, \tilde{m})$ and $K(\Theta, x, \tilde{m})$ are the kernel functions defined by:

$K_{\text {ext }}(x, \tilde{m})=\frac{3}{4} \frac{Q_{\text {ext }}(x)}{x}$ 
$K(\Theta, x, \tilde{m})=\frac{3}{2} \frac{i_{1}+i_{2}}{x^{3}}$.

In Eqs. (6) and (7), $Q_{\text {ext }}$ is the extinction efficiency factor, and $i_{1}$ and $i_{2}$ are the intensity functions. In case of light scattering by spherical particles, these functions can be computed by the Mie theory. Otherwise, other formulations must be employed, such as the T-matrix method (Mishchenko et al., 2002) for randomly oriented spheroids (Dubovik et al., 2006; Kobayashi et al., 2010).

To retrieve the aerosol properties, Eq. (3) is iteratively inverted. The idea of the method is to iteratively eliminate the multiple scattering term $q(\Theta)$ from the ratio $R(\Theta)$ to recover the single scattering term $\beta(\Theta)$. In each of the iterations, the algorithm obtains the aerosol volume distribution $v(r)$ by inversion of the aerosol optical depth $\tau_{\mathrm{a}}(\lambda)$ and the single scattering coefficient $\beta_{\mathrm{a}}(\Theta)$.

In each iteration step, the retrieved volume distribution is used as input for the radiative transfer code in order to simulate $R(\Theta)$, which is compared with the experimental $R(\Theta)$ to evaluate the root mean square difference $\epsilon(R)$. The process is repeated until $\epsilon(R)$ is less than a given threshold; otherwise, the solution is rejected.

In this iteration scheme, the complex refractive index $\tilde{m}$ is also evaluated together with $v(r)$. Once $v(r)$ and $\tilde{m}$ are optimized by minimization of a quadratic form (Dubovik and King, 2000), the aerosol single scattering albedo can be estimated by:

$\omega(\lambda)=\frac{\tau_{\mathrm{a}, \mathrm{sca}}(\lambda)}{\tau_{\mathrm{a}, \mathrm{ext}}(\lambda)}$

where $\tau_{\mathrm{a}, \text { sca }}$ is obtained by an equivalent integral to Eq. (4), substituting $K_{\text {ext }}(x, \tilde{m})$ for $K_{\mathrm{sca}}(x, \tilde{m})$, being $K_{\mathrm{sca}}(x, \tilde{m})$ the scattering kernel function.

Finally, we also need to link the magnitudes described in the radiative transfer model ( $F$ and $E(\Theta)$ ) with actual measurements performed by the radiometers, i.e. the raw voltages or digital signals when pointing the radiometer to the sun (direct sun component or $S\left(\theta_{0}, \phi_{0}\right)$ ) and at different points of the sky (sky diffuse component or $S\left(\theta_{0}, \phi\right)$ ). For the sky diffuse component, the radiometer is moved along the solar almucantar plane, keeping the zenith angle constant and equal to the solar zenith angle $\left(\theta_{0}\right)$ and varying the azimuthal angle $(\phi)$. To get corresponding $F$ and $E(\Theta)$ or $R(\Theta)$, calibration factors $S_{0}$ and $\Delta \Omega$ must be introduced.

In the following section we will summarise the different strategies adopted by SKYNET and AERONET to implement the retrieval algorithms and obtain the calibration factors.

\subsubsection{SKYNET and AERONET strategies}

The specific inversion algorithm used by SKYNET is the Skyrad.pack, currently version 4.2 , based on a previous version described by Nakajima et al. (1996). The algorithm is composed of the radiative transfer model described by Nakajima and Tanaka (1988) and an inversion method similar to the model described by Dubovik and King (2000). In version 4.2, the kernel functions are only computed with the Mie theory for a spherical particle. New versions of the SKYRAD package will include non-sphericity effects (Kobayashi et al., 2010) similar to AERONET. For the field Prede radiometer, the $S_{0}$ calibration is obtained by using an improved Langley plot method (Tanaka et al., 1986; Campanelli et al., 2004a). For the retrieval of $\Delta \Omega$, the solar disk scanning method (Boi et al., 1999) is used.

In turn, the specific inversion strategy used by AERONET has been extensively described in a number of studies (Dubovik et al., 1995, 2000, 2006; Dubovik and King, 2000). Although the first algorithm used by AERONET was the Skyrad.pack described by Nakajima et al. (1996), an improved algorithm (Version 1.0) was developed by Dubovik and King (2000). The new version employed two spherical and spheroidal aerosol models (Dubovik et al., 2002a) by using different kernel look-up tables. In this algorithm, the inversion was designed as a search of best fit of all data, considering sun and sky measurements and a priori constrains together on a single set of multisource data with independent errors to account for different levels of uncertainty. For the solution search, two minimization techniques were implemented: a matrix inversion method (single value decomposition) and a steepest descent or gradient search method (Dubovik and King, 2000). Further developments led to the delivery of current Version 2.0 algorithm (Dubovik et al., 2006). In this case, the aerosols are described by a volume distribution of randomly oriented, polydisperse spheroids. To create the precomputed kernels matrices, the T-matrix code (Mishchenko et al., 2002) and the approximate geometric optics integral equation method (Yang et al., 1996) were used, with an axis ratio distribution given by Dubovik et al. (2006) and assuming an equal presence of prolate and oblate spheroids.

For the direct component calibration of the field Cimel sunphotometers, calibration transfers from a master radiometer are periodically performed (Holben et al., 1998) although the improved method has been also previously applied with good results (Campanelli et al., 2007). For the diffuse component calibration, the standard radiometric method can be used (Holben et al., 1998). The radiometric calibration is performed with an integrating sphere of known radiance; hence, the sky diffuse radiance $E(\Theta)\left(\mathrm{Wm}^{-2} \mathrm{~nm}^{-1} \mathrm{sr}^{-1}\right)$ is directly obtained. For this study, the calibrations provided by RIMA/AERONET have been used.

\subsubsection{Sensitivity and error analysis}

Kim et al. (2004) already performed an error and sensitivity analysis of the current version of the Skyrad.pack algorithm. In this analysis, the ratio $R(\Theta)$ was forward modelled with the radiative transfer model by using a set of nominal input 
conditions, with varying values of aerosol optical depth and zenith angles. The simulated $R(\Theta)$ was inverted and the solutions were compared with the original inputs (volume distribution, aerosol optical depth and single scattering albedo). No sensitivity study is available for the refractive index or asymmetry parameter.

Following Kim et al. (2004), the differences between given and retrieved aerosol optical depth at $500 \mathrm{~nm}$ were less than 0.02 , suggesting that the retrievals were accurate enough. The differences for the volume distributions were significantly large when particle radii were smaller than $0.1 \mu \mathrm{m}$. In both cases, the SKYRAD retrievals overestimated the given distributions.

In the case of the single scattering albedo, the difference was minimum when large zenith angles and high optical depths were involved, although it was as large as 0.08 when both zenith angle and aerosol optical depth were low (30 degrees and 0.2 respectively). The retrieved single scattering was always underestimated.

Dubovik et al. (2000) analysed the maximum accuracy expected for the AERONET aerosol retrievals of the volume distribution, complex refractive index and single scattering albedo, after numerical simulations for three aerosol models (dust, biomass burning and maritime) for a given set of conditions. The results showed that the errors were mainly dependent on the aerosol optical depth and the scattering angle available range, being larger for low aerosol burden conditions.

For the volume distribution, the inversions were rather well calculated in almost all situations, although the error was dependent on the particle size. For the interval $0.1 \leq r \leq 7 \mu \mathrm{m}$, the retrieval errors do not exceed $10 \%$ in the maxima but could increase up to $35 \%$ in the minima. Outside this intermediate range the errors increased, rising up to 80-100\% or higher for $r \leq 0.1 \mu \mathrm{m}$ and $r \geq 7 \mu \mathrm{m}$ (Dubovik et al., 2002b).

In the case of single scattering albedo, real refractive index and imaginary refrective index, the accuracy was maximum (0.03, 0.04 and 30-50\% respectively) only for high aerosol loading (AOD440 $\geq 0.5$ ) and for a solar zenith angle $>50^{\circ}$. For AOD $440 \leq 0.2$, the accuracy drops down to $0.05-0.07$ for the single scattering albedo, 0.05 for the real part of the refractive index, and 80-100\% for the imaginary part of the refractive index (Dubovik et al., 2002b).

\subsection{The ceform module}

In order to elaborate the Cimel data, the original SKYRAD version 4.2 was adapted. The SKYRAD package consists of two different modules called dtform and sproc. The dtform module formats the Prede POM data so it can be fed in the processing module sproc. Therefore, we substituted the dtform module with our own code (called ceform). The ceform module formats the Cimel data, applies quality filters and accounts for temperature effects.
The formatting of Cimel data consists of computing the normalized ratio seen in Eq. (3). For the optical air mass, the formula of Kasten et al. (1989) was adopted. In the current version, only one single value of the optical air mass has been used for all the atmospheric components. The zenith angle of the sun was corrected for refraction effects (Michalsky et al., 1988). To compute the solar declination and the eccentricity correction factor of the Earth orbit (related to the distance between the Sun and the Earth), the Spencer (1971) expressions have been implemented (Iqbal, 1983).

The solar irradiance at the ground is also needed in Eq. (3). Provided that the instrument calibration $\left(S_{0}\right)$ is available, the solar irradiance at ground can be obtained from the instrument signal at ground $(S)$ and the solar irradiance at the top of the atmosphere $\left(F_{0}\right)$. In turn, $F_{0}$ was obtained from the SMARTS version 2.9 model extraterrestrial spectrum (Gueymard , 2001). The columnar ozone burden was obtained from OMI sensor and correspondingly interpolated for any instantaneous measurement (Ozone Monitoring Instrument website, 2011).

The ceform module also applies a symmetry check between the right and left sides of the almucantar plane (Holben et al., 1998). This filter is intended to remove measurement angles affected by clouds, mainly. More specifically, the asymmetry threshold has been currently set at a value of $10 \%$. The asymmetric pairs are removed from the inversion process.

For the temperature correction accounted in ceform, specific coefficients were obtained for this specific instrument. To retrieve these coefficients, we employed a thermal chamber to control the Cimel optical head temperature. The temperature was varied between $5{ }^{\circ} \mathrm{C}$ and $45^{\circ} \mathrm{C}$. During the experiment, the Cimel head measured the radiance emitted by an stabilized light source (integrating sphere) in a darkroom (Taviro, 2011).

Once the thermal coefficients were obtained, the corrected signal $S_{25}(\lambda)$ can be obtained by using the following expression:

$S_{25}(\lambda)=S_{T}(\lambda)\left[1+\frac{k_{T}(\lambda)}{100}(T-25)\right]^{-1}$.

In this equation, $S_{T}$ refers to the signal measured at any temperature $T$, and $S_{25}$ represents the corrected signal at the reference temperature $\left(25^{\circ} \mathrm{C}\right) . k_{T}(\lambda)$ is the thermal coefficient, expressed in $\%{ }^{\circ} \mathrm{C}$. These variables depend on wavelength $(\lambda)$. The highest dependence is found at 1020 and $870 \mathrm{~nm}$ channels. The thermal coefficients for the other channels could be neglected. Our $1020 \mathrm{~nm}$ value was very similar to that of Holben et al. (1998). The values were also similar to the coefficients provided by the photodiode manufacturer, although the latter do not include the thermal effects due to other elements of the Cimel optical system. 


\subsection{Comparison methodology}

In order to compare the SKYRAD and AERONET retrievals, a 1 month Cimel CE318 database has been used. The data were acquired in the AERONET Burjassot site (Valencia, Spain) during February 2011. This period included very contrasting aerosol scenarios, with a large range of aerosol optical depth produced in a short time. No important influence of non-spherical particles was detected, as no dust intrusions occur during this period. The sphericity factor provided by AERONET confirmed this suspicion during the high aerosol optical depth episode.

The pre- and post-calibration of the used Cimel instrument was provided by RIMA/AERONET. The pre- and postcalibration factors are interpolated to get the effective calibration at any given time. Furthermore, only AERONET 1.5 level data has been used for this comparison, though the level is not critical for such a comparative study.

Different statistical indicators have been employed for this comparison: relative and absolute root mean square deviation (rmsd) and mean bias deviation (mbd) to represent the mean differences. The standard deviation of differences (std) has been also computed and represents the variability of the differences around the mean values. Percentile 95 (u95) was also computed. Equations (10) to (12) show these estimators. Moreover, the Chauvenet criterion has been applied to avoid outliers in the sample, by removing any point with a difference with the mean greater than 3 times the sample standard deviation. In the following expressions, $x_{i 0}$ and $x_{i}$ refer to any property compared from the reference and secondary instruments, respectively, and $\Delta_{i}$ represents the difference between two simultaneous $x_{i 0}$ and $x_{i}$.

$$
\begin{aligned}
& \mathrm{rmsd}=\sqrt{\frac{1}{N} \sum_{i=1}^{N}\left(x_{0 i}-x_{i}\right)^{2}}=\sqrt{\frac{1}{N} \sum_{i=1}^{N} \Delta_{i}^{2}} \\
& \operatorname{mbd}=\bar{\Delta}=\frac{1}{N} \sum_{i=1}^{N}\left(x_{0 i}-x_{i}\right)=\frac{1}{N} \sum_{i=1}^{N} \Delta_{i} \\
& \operatorname{std}=\sqrt{\frac{1}{N} \sum_{i=1}^{N}\left(\Delta_{i}-\bar{\Delta}\right)^{2}}
\end{aligned}
$$

\section{Results}

\subsection{Analysis of the episode conditions}

Based on Estellés et al. (2007a), February can be considered a relatively clean month (mean AOD500 of $0.16 \pm 0.12$ ) but still not very different to the annual average (mean AOD500 of $0.19 \pm 0.13$ ). The mean AOD (at $440 \mathrm{~nm}$ ) during the period used in the present study is $0.15 \pm 0.16$, slightly lower and more variable than the average February month period.

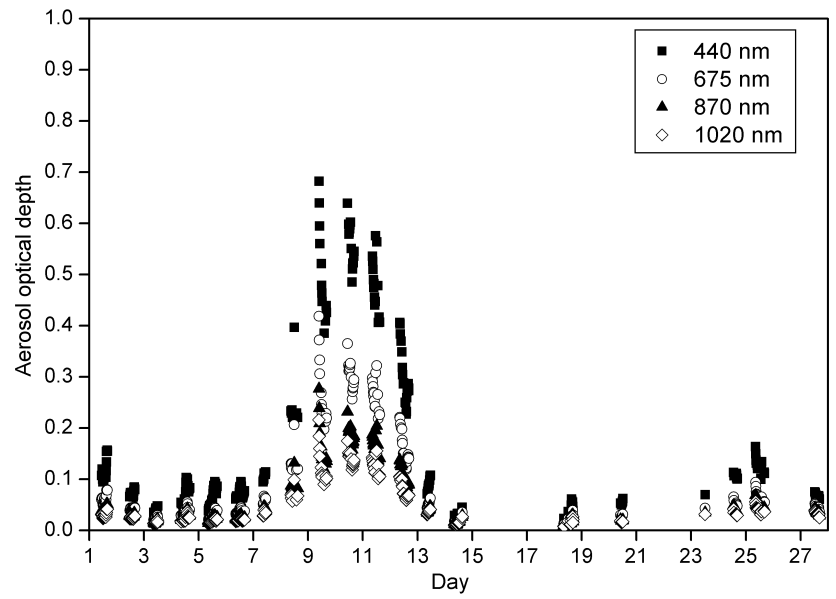

Fig. 1. Evolution of the spectral aerosol optical depth obtained from the AERONET inversions during the period of study (February 2011).

In Fig. 1 the aerosol optical depth at the four main Cimel channels is represented for the period used in this study.

A case of severe pollution was identified during February 2011 and described elsewhere (Segura et al., 2011). This episode is easily identified in Fig. 1, where AERONET AOD retrievals are plotted for the four main channels. The AOD440 is very low (less than 0.1) during days 2 to 6 , increasing steadily and reaching the maximum (up to 0.6) during days 9 to 12, and getting cleaner again on day 14 after the passage of a front. From day 15 on, the series is frequently interrupted by the effect of weather (clouds). It must be noted however that no strong dust intrusions occurred during this period, avoiding non-sphericity effects in the comparison. Otherwise, this would be an issue because version 4.2 does not include aerosol non-sphericity effects (Olmo et al., 2006).

\subsection{Optical and radiative properties}

In Table 1 we show the quantitative comparison between aerosol optical depth (retrieved from the inversion), single scattering albedo (SSA), refractive index (RRI and IRI for real and imaginary parts, respectively) and asymmetry parameter $(g)$, for all the period.

The aerosol optical depth deviation is within the combined uncertainties of both methods, estimated to be $\sim 0.01-0.02$ in AERONET (Eck et al., 1999). The deviation is higher at $440 \mathrm{~nm}$ and lower at $870 \mathrm{~nm}$ in good agreement with previous comparisons of AOD between Prede (elaborated by SKYNET) and Cimel (elaborated by AERONET) (Sano et al., 2003; Evgenieva et al., 2008; Campanelli et al., 2004b). It is also in very good agreement with our previous findings involving direct sun measurements only (Estellés et al., 2010, 2012). The u95 percentile shows that some data differ from AERONET, a difference slightly higher than 0.02 for $440 \mathrm{~nm}$. 
Table 1. Statistics of the differences between AERONET and SKYRAD properties. The number of data samples is 103 .

\begin{tabular}{|c|c|c|c|c|c|}
\hline$\lambda(\mathrm{nm})$ & $\operatorname{rmsd}(\%)$ & rmsd & mbd & std & u95 \\
\hline \multicolumn{6}{|c|}{ AOD } \\
\hline 440 & 7.1 & 0.013 & -0.0066 & 0.0011 & 0.023 \\
\hline 675 & 7.5 & 0.0069 & 0.0036 & 0.00062 & 0.013 \\
\hline 870 & 3.9 & 0.0024 & 0.0004 & 0.00025 & 0.005 \\
\hline 1020 & 4.7 & 0.0023 & -0.0018 & 0.00015 & 0.003 \\
\hline \multicolumn{6}{|c|}{ SSA } \\
\hline 440 & 5.1 & 0.045 & -0.013 & 0.045 & 0.091 \\
\hline 675 & 13 & 0.12 & -0.110 & 0.058 & 0.15 \\
\hline 870 & 11 & 0.094 & -0.082 & 0.046 & 0.12 \\
\hline 1020 & 8.5 & 0.068 & 0.015 & 0.069 & 0.14 \\
\hline \multicolumn{6}{|c|}{ RRI } \\
\hline 440 & 6.7 & 0.097 & 0.086 & 0.046 & 0.13 \\
\hline 675 & 6.5 & 0.093 & 0.084 & 0.041 & 0.12 \\
\hline 870 & 5.8 & 0.084 & 0.074 & 0.041 & 0.11 \\
\hline 1020 & 5.3 & 0.077 & 0.066 & 0.043 & 0.10 \\
\hline \multicolumn{6}{|c|}{ IRI } \\
\hline 440 & 79 & 0.013 & -0.0094 & 0.0093 & 0.021 \\
\hline 675 & $>100$ & 0.022 & -0.019 & 0.012 & 0.031 \\
\hline 870 & $>100$ & 0.020 & -0.017 & 0.010 & 0.027 \\
\hline 1020 & 65 & 0.012 & -0.0081 & 0.010 & 0.022 \\
\hline \multicolumn{6}{|c|}{$g$} \\
\hline 440 & 6.2 & 0.043 & 0.033 & 0.029 & 0.068 \\
\hline 675 & 5.0 & 0.032 & 0.019 & 0.027 & 0.057 \\
\hline 870 & 4.5 & 0.028 & 0.061 & 0.028 & 0.057 \\
\hline 1020 & 4.9 & 0.030 & -0.0035 & 0.031 & 0.062 \\
\hline
\end{tabular}

The maximum std is found also for $440 \mathrm{~nm}$ channel, although the low value (0.0011) shows that the differences are rather systematic.

Higher differences are observed at other parameters such as SSA and refractive index. For SSA, the root mean square deviation is lower than $10 \%$ at 440 and $1020 \mathrm{~nm}$, with a maximum mean bias deviation of -0.11 at $675 \mathrm{~nm}$. The rmsd varies between 0.07 and 0.12 , and $5 \%$ of the values were higher than 0.10-0.15. In all the channels except for $1020 \mathrm{~nm}$, the SKYRAD values exceed those of AERONET.

For the real part of the refractive index, the differences are $5-7 \%$ for all channels. The imaginary part of the refractive index has the highest deviation of the studied parameters, with a percent difference that exceeds $100 \%$ for channels 675 and $870 \mathrm{~nm}$. In both real and imaginary parts, SKYRAD retrieves lower indexes than AERONET. This fact is in agreement with Che et al. (2008) for the Prede and Cimel comparison, although in their comparison they got lower deviation. In any case, we must bear in mind that Che et al. (2008) study was performed in very turbid conditions.
The asymmetry factor $(g)$ has been estimated a posteriori from the phase function retrieved by SKYRAD, and is used here as a compact parameter for the comparison. In this case, the relative differences are 4.5-6.2\%. The rmsd is lower than 0.05 for all channels. Once again, the $g$ factor obtained by SKYRAD is lower than the AERONET product for all the channels.

The results shown in Table 1 were averaged for the complete February period. Kim et al. (2004) and Dubovik and King (2000) pointed out the higher retrieval errors that appear when low aerosol burdens are present. Therefore, we have separated the statistics for days with a AOD440 $<0.2$ and AOD440 $>0.2$. The respective results are shown in Table 2. Only the rmsd is shown, in absolute and relative terms.

In general, the differences found for AOD $>0.2$ are much lower than for $\mathrm{AOD}<0.2$, and in some cases the improvement in the absolute rmsd is one order of magnitude. The change in the relative rmsd is important too, although it depends on the parameter studied.

In the case of the AOD, both differences are within the nominal uncertainty, being higher for shorter wavelengths. The deviations in the absolute rmsd are slightly higher for turbid conditions (0.003-0.014) but lower if the relative rmsd is used $(2.7-5.3 \%)$.

The SSA differences for turbid conditions are much lower than for the clear conditions, with an absolute and relative rmsd of $0.025-0.049$ and $2.8-5.3 \%$. These results are within the $0.05-0.07$ error estimation given by Dubovik et al. (2002b) for the AOD440 $<0.2$ condition.

The same effect is present in the RRI and IRI, with much higher deviations found in the imaginary part. For the high AOD conditions, the IRI differences are lower than $80 \%$. For RRI, the absolute rmsd is lower than 0.04 , within the expected 0.05 threshold estimated by Dubovik et al. (2002b) for AOD440 $=0.2$. In the case of the asymmetry parameter, the relative rmsd is lower than $1.5 \%$.

Therefore, our resuls are very consistent with previous sensitivity studies performed by Dubovik et al. (2002b) and Kim et al. (2004) for the individual network methodologies. Within the quality thresholds recommended by them, both inversion algorithms are able to provide comparable results. However, the differences increase beyond acceptable limits when results obtained under conditions of low optical depth are compared.

\subsection{Volume distributions}

To compare the volume distributions obtained by both methodologies, we have interpolated the SKYRAD retrievals to the AERONET radius bins, so the statistical estimators could be computed for each of these radius bins. The absolute and relative rmsd for the whole period have been plotted in Fig. 2. The top panel figure clearly shows that the deviation is very high at the endings of the distributions, with maximum values of $200 \%$. Between 0.15 and $5 \mu \mathrm{m}$, the deviation 
Table 2. Statistics of the differences between AERONET and SKYRAD properties separated by the AOD level.

\begin{tabular}{|c|c|c|c|c|}
\hline \multirow[b]{2}{*}{$\lambda(\mathrm{nm})$} & \multicolumn{2}{|c|}{ AOD $440<0.2$} & \multicolumn{2}{|c|}{$\mathrm{AOD} 440>0.2$} \\
\hline & $\operatorname{rmsd}(\%)$ & rmsd & $\operatorname{rmsd}(\%)$ & rmsd \\
\hline \multicolumn{5}{|c|}{ AOD } \\
\hline 440 & 15 & 0.012 & 3.0 & 0.014 \\
\hline 675 & 4.6 & 0.0018 & 5.3 & 0.013 \\
\hline 870 & 3.0 & 0.0009 & 2.8 & 0.0046 \\
\hline 1020 & 7.5 & 0.0018 & 2.7 & 0.0034 \\
\hline \multicolumn{5}{|c|}{ SSA } \\
\hline 440 & 5.6 & 0.048 & 3.4 & 0.032 \\
\hline 675 & 15 & 0.13 & 3.7 & 0.034 \\
\hline 870 & 12 & 0.10 & 5.3 & 0.049 \\
\hline 1020 & 10.0 & 0.076 & 2.8 & 0.025 \\
\hline \multicolumn{5}{|c|}{ RRI } \\
\hline 440 & 7.6 & 0.11 & 2.3 & 0.034 \\
\hline 675 & 7.3 & 0.10 & 2.0 & 0.028 \\
\hline 870 & 6.6 & 0.096 & 1.0 & 0.015 \\
\hline 1020 & 6.0 & 0.089 & 0.4 & 0.005 \\
\hline \multicolumn{5}{|c|}{ IRI } \\
\hline 440 & 75 & 0.014 & 76 & 0.0060 \\
\hline 675 & $>100$ & 0.026 & 72 & 0.0065 \\
\hline 870 & $>100$ & 0.022 & 83 & 0.0072 \\
\hline 1020 & 64 & 0.014 & 35 & 0.0039 \\
\hline \multicolumn{5}{|c|}{$g$} \\
\hline 440 & 7.3 & 0.050 & 1.1 & 0.0079 \\
\hline 675 & 5.7 & 0.036 & 0.9 & 0.0062 \\
\hline 870 & 5.1 & 0.031 & 1.1 & 0.0074 \\
\hline 1020 & 5.6 & 0.034 & 1.4 & 0.0086 \\
\hline
\end{tabular}

is lower than $20 \%$, with an average value of $13 \%$. This is in agreement with Dubovik et al. (2002b), as they estimated the error in the retrieval to be $10-35 \%$ within the $0.1-7 \mu \mathrm{m}$ interval, and increasing to $80-100 \%$ for the rest of the retrieved radius interval.

As the distribution functions from AERONET go down to zero in the extremes $(0.05$ and $15 \mu \mathrm{m})$, the relative rmsd behaviour for the tails of the distribution was partly expected. To avoid the increase of the relative deviation in the very extremes, the absolute deviation has also been plotted in the bottom panel. From Fig. 2 it is clear that the deviation in the distributions increases for radius smaller than $0.01-0.02 \mu \mathrm{m}$ and for radius bigger than $0.06-0.07 \mu \mathrm{m}$.

To look in detail at the distribution differences and the aerosol burden limitations, in Fig. 3 we have plotted three representative cases of our dataset. The top, middle and bottom panels correspond to the distributions obtained on days 4, 11 and 14 February 2011, at 10:37, 10:38 and

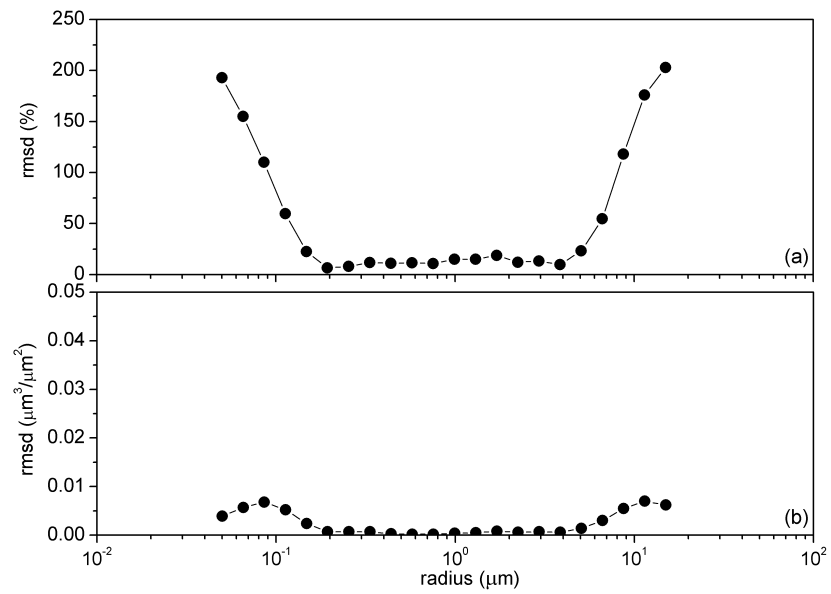

Fig. 2. Relative (a) and absolute (b) root mean square deviation between the SKYRAD and AERONET volume distribution functions.

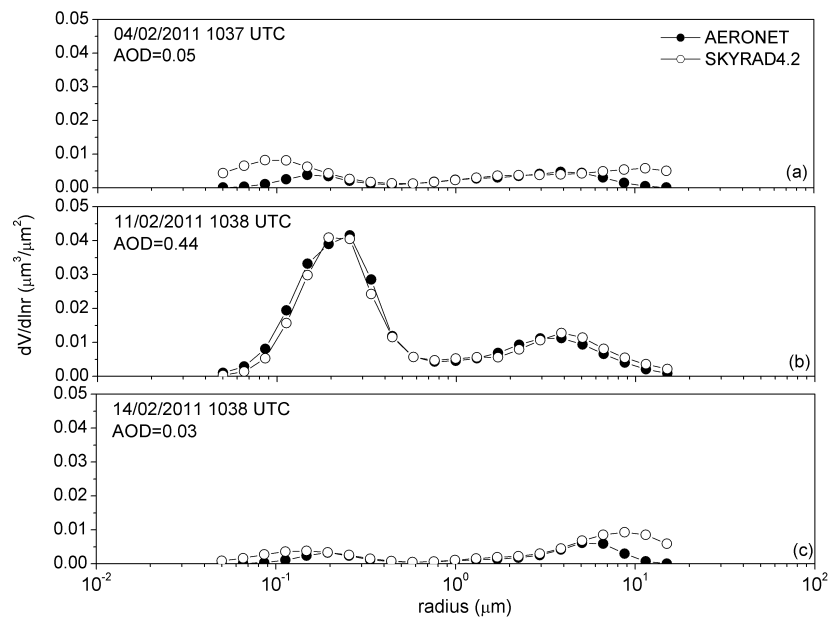

Fig. 3. Comparison between SKYRAD and AERONET distributions for three representative cases of the dataset: before, during and after the pollution episode.

10:38 UTC, respectively. The corresponding AODs at this time were $0.05,0.44$ and 0.03 , respectively. These three cases represent the three phases of the pollution episode highlighted in Fig. 1.

In the top and bottom panels, the volume distributions represent two cases of very low aerosol burdens. It is well known that the inversion products have a very high uncertainty in these conditions (Dubovik et al., 2000) especially in parameters such as the imaginary part of the refractive index. Therefore, the differences were expected to be relatively high in these conditions. In both situations, the maximum deviations are found for the tails of the distributions, as it has been shown in Fig. 2. Also, the SKYRAD fine and coarse modes appear to be slightly displaced in respect to AERONET modes.

On the contrary, the comparison between SKYRAD and AERONET distributions looks very good for the 11 February 


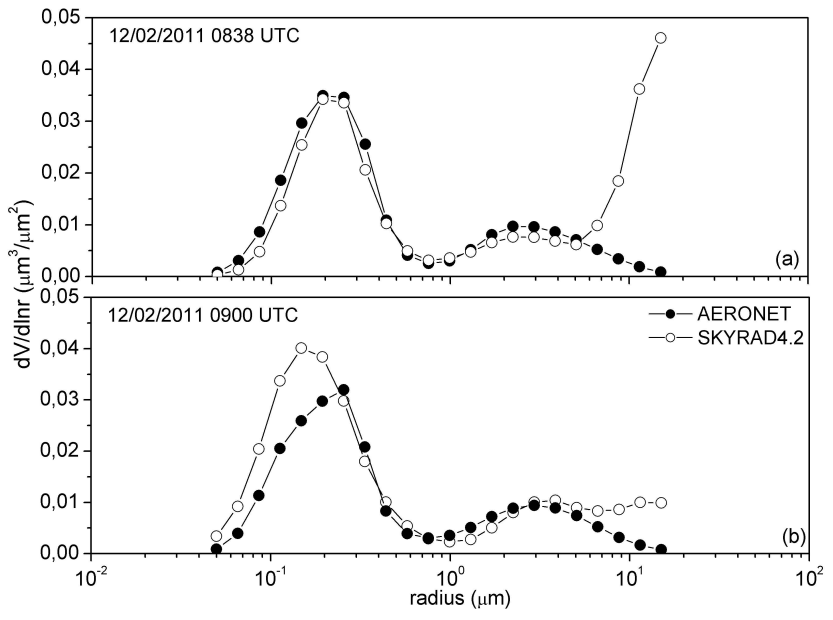

Fig. 4. Two representative cases of type II SKYRAD solutions with a second coarse mode that leaves the distributions tails open.

case, when a high AOD was reached $(0.44$ at $440 \mathrm{~nm})$. Both modes are identically described, with minimum differences in the tails of the functions.

If we analyze all the distributions obtained during days 9 to 12 February (corresponding to AOD440 higher than 0.2), $60 \%$ of cases are similar to the bimodal distributions shown in the middle panel in Fig. 3 (defined here as type I distributions). The remaining $40 \%$ of cases correspond to SKYRAD distributions with a trimodal shape (defined as type II distributions) while the AERONET distributions continued to have a bimodal shape.

Two illustrative cases of type II distributions are shown in Fig. 4. In Fig. 4a, a strongly dominant second coarse mode is noticed (defined as type IIa distribution). On the contrary, the second coarse mode shown in Fig. $4 \mathrm{~b}$ (defined as type IIb distribution), though discrepant with AERONET, looks plausible. From the $40 \%$ type II cases present during days 9 to 12 , $50 \%$ were due to type IIb.

The discrepancy between SKYRAD and AERONET volume retrievals in the tails of the distributions is long known and was also described by Che et al. (2008) for an AERONET and SKYNET comparison in Beijing. The mean volume distribution found by Che et al. (2008) with a Prede was trimodal, although AERONET inversions of Cimel data showed a mean bimodal distribution. They hinted at few differences that could be responsible for such deviations: number of radius bins used by the two methodologies, nonsphericity effects and a different combination of available channels in the Prede and Cimel instruments.

From the factors invoked by Che et al. (2008), the channel configuration effect has been discarded in our comparison, as the retrievals have been performed with the same Cimel channels than AERONET. The non-sphericity effect cannot be discarded a priori, as the current SKYRAD version 4.2 does not account for non-sphericity, as in the case of Che et al. (2008). However, this should not be an issue for the studied dataset, as no important sources of remote or local dust affected our site during the high AOD period. In fact, the sphericity factor obtained by AERONET during the high AOD days (9-12 February) is $99 \pm 2 \%$, in relation to the pollution episode.

In summary, when the AOD is high (in this study the threshold was set to 0.2 for AOD440) the volume distributions retrieved with SKYRAD have a good comparison with AERONET when bimodal shapes are retrieved. However, even with the use of the same data and calibration, in some instances a second coarse mode appears in the volume distribution and eventually becomes strongly dominant. In the latter cases, the deviation between SKYRAD and AERONET functions increases, though we still cannot point out at the responsible process in the inversion algorithms. Hence, more research needs to be done.

\section{Conclusions}

In this study we have assessed the performance of the SKYRAD version 4.2 inversion algorithm in comparison to AERONET when the same Cimel CE318 data and calibration set was used, thus avoiding the effect of several instrumental differences present in previous comparisons, such as wavelength configuration, temperature dependences, calibration or pointing accuracies. To adapt the SKYRAD version 4.2 algorithm to the Cimel CE318 data, we implemented a new pre-processing program (called ceform). The ceform program formats the Cimel data and applies a basic set of quality control filters, such as the symmetry of the almucantar measurements.

In order to validate the ceform-SKYRAD method, a Cimel CE318 one month database obtained in Burjassot (Spain) during February 2011 has been inverted, and the retrievals have been compared with AERONET, in order to assess the differences between both inversion methodologies when exactly the same data and calibration is used. The selected dataset is representative of different conditions at the site, although dust cases were not present, avoiding non-sphericity effects in the comparison. During this period, an episode of pollution occurred. This episode was recognizable by an intense period of high aerosol optical depth, surpassing the recommended threshold for reliable inversions. This scenario allowed us to compare both methods in different conditions of turbidity. A total number of 103 inversions were used in the comparison.

The aerosol optical depth compared well (0.002-0.013 for all the wavelengths) within the combined uncertainty, with higher deviation at $440 \mathrm{~nm}$. The single scattering albedo and real and imaginary parts of the refractive index got a relative root mean square deviation of $5-13 \%, 5-7 \%$ and $65-$ $160 \%$, respectively. Clearly, the imaginary part of the refractive index got the highest differences, although this result 
was expected due to the involved uncertainties of this parameter. The refractive indexes retrieved by SKYRAD were lower than AERONET. In the case of the asymmetry parameter, the relative deviation was $4.5-6.0 \%$. In general, the trends were consistent with those published by other authors for a Prede-Cimel comparison, although our comparison was partly performed in low turbidity conditions.

When dividing the comparison for low and high aerosol optical depth situations, it was made clear that the inversions performed for AOD440 $>0.2$ were much more similar to AERONET than those performed at AOD440 $<0.2$ conditions. It is worthwhile noting that the single scattering albedo, real refractive index and imaginary refractive index deviations diminished to $0.03-0.05$ (3-5\%), 0.015-0.005 $(0.3-2 \%)$ and $0.004-0.007(35-80 \%)$ respectively. These differences were very consistent with the sensitivity and error analysis performed by the Dubovik et al. (2002b) and Kim et al. (2004) studies for the AERONET and SKYRAD inversion algorithms, respectively. Therefore, both retrieval algorithms are shown to be consistent when the minimum AOD threshold is respected, although the differences should be still addressed in order to improve their relative performance. On the other hand, the asymmetry parameter was very comparable, with a 1-2\% relative deviation.

The volume distributions obtained by SKYRAD also compared well with the AERONET retrievals. When the comparison was performed in low AOD conditions, the SKYRAD modes were slightly displaced in relation to the corresponding fine and coarse modes in the AERONET distributions, although the general shape of the distribution was similar. When the minimum AOD threshold was respected the comparison improved, although in some SKYRAD instances a second coarse mode appear. This second mode did not appeared in AERONET distributions, at least for the cases studied. Eventually, this coarse mode could become strongly dominant, leading to important deviations from AERONET, possibly in relation to cirrus contamination. These particular cases will be studied in more detail in the future, through the implementation of further quality filters, and the comparison of extended databases with other experimental techniques.

Acknowledgements. The authors acknowledge RIMA and AERONET networks for providing retrievals and CE318 calibration coefficients. V. Estellés acknowledges the Spanish Ministry of Science and Innovation (MICINN) for the research contract under the Juan de la Cierva programme (JCI-2009-04455). The GOTA group at the University of La Laguna has been funded by project FORCAN CGL2008-04740. The Solar Radiation Group at the University of Valencia has been supported by projects CGL2011-24290 and CGL2009-07790 from the MICINN, and PROMETEO/2010/064 from the Valencia Autonomous Government.

Edited by: A. Kokhanovsky

\section{References}

AERONET website: http://aeronet.gsfc.nasa.gov/, last access: October 2011.

Boi, P., Tonna, G., Dalu, G., Nakajima, T., Olivieri, B., and Pompei, A.: Calibration and data elaboration procedure for sky irradiance measurements, Appl. Optics, 38, 896-907, 1999.

Campanelli, M., Nakajima, T., and Olivieri, B.: Determination of the solar calibration constant for a sun-sky radiometer: Proposal of an in situ procedure, Appl. Optics, 43, 651-659, 2004a.

Campanelli, M., Gobbi, G., Tomasi, C., and Nakajima, T.: Intercomparison between aerosol characteristics retrieved simultaneously with a Cimel and Prede sun-sky radiometers in Rome (Tor Vergata AERONET site), Óptica Pura y Aplicada, 37, 31593164, 2004b.

Campanelli, M., Estells, V., Tomasi, C., Nakajima, T., Malvestuto, V., and Martínez-Lozano, J. A.: Application of the SKYRAD Improved Langley plot method for the in situ calibration of CIMEL Sun-sky photometers, Appl. Optics, 46, 2688-2702, 2007.

Che, H., Shi, G., Uchiyama, A., Yamazaki, A., Chen, H., Goloub, P., and Zhang, X.: Intercomparison between aerosol optical properties by a PREDE skyradiometer and CIMEL sunphotometer over Beijing, China, Atmos. Chem. Phys., 8, 3199-3214, doi:10.5194/acp-8-3199-2008, 2008.

Dubovik, O., Lapyonok, T. V., and Oshchepkov, S. L.: Improved technique for data inversion: Optical sizing of multicomponent aerosols, Appl. Optics, 34, 8422-8436, 1995.

Dubovik, O. and King, M. D.: A flexible inversion algorithm for retrieval of aerosol optical properties from sun and sky radiance measurements, J. Geophys. Res., 105, 20673-20696, 2000.

Dubovik, O., Smirnov, A., Holben, B., King, M. D., Kaufman, Y. J., Eck, T. F., and Slutsker, I.: Accuracy assessment of aerosol optical properties retrieved from Aerosol Robotic Network (AERONET) sun and sky radiance measurements, J. Geophys. Res., 105, 9791-9806, 2000.

Dubovik, O., Holben, B., Lapyonok, T., Sinyuk, A., Mischenko, M. I., Yang, P., and Slutsker, I.: Non-spherical aerosol retrieval method employing light scattering by spheroids, Geophys. Res. Lett., 29, 10, doi:10.1029/2001GL014506, 2002a.

Dubovik, O., Holben, B., Eck, T. F., Smirnov, A., Kaufman, Y. J., King, M. D., Tanre, D., and Slutsker, I.: Variability of Absorption and Optical Properties of Key Aerosol Types Observed in Worldwide Locations, J. Atmos. Sci., 59, 590-608, 2002b.

Dubovik, O., Sinyuk, A., Lapyonok, T., Holben, B., Mischenko, M. I., Yang, P., Eck, T., Volten, H., Muñoz, O., Veihelmann, B., van der Zande, W. J., Leon, J. F., Sorokin, M., and Slutsker, I.: Application of spheroid models to account for particle nonsphericity in remote sensing of desert dust, J. Geophys. Res., 111, D11208, doi:10.1029/2005JD006619, 2006.

Eck, T., Holben, B., Reid, J. S., Dubovik, O., Smirnov, A., O'Neill, N. T., Slutsker, I., and Kinne, S.: Wavelength dependence of the optical depth of biomass burning urban and desert dust aerosols, J. Geophys. Res., 104, 31333-31349, doi:10.1029/1999JD900923, 1999.

ESR network website: http://www.euroskyrad.net/, last access: October 2011 
Estellés, V., Utrillas, M. P., Martínez-Lozano, J. A., Alcántara, A., Alados-Arboledas, L., Olmo, F. J., Lorente, J., de Cabo, X., Cachorro, V., Horvath, H., Labajo, A., Sorribas, M., Díaz, J. P., Díaz, A. M., Silva, A. M., Elias, T., Pujadas, M., Rodrigues, J. A., Cañada, J., and García, Y.: Intercomparison of spectroradiometers and Sun photometers for the determination of the aerosol optical depth during the VELETA-2002 field campaign, J. Geophys. Res., 111, D17207, doi:10.1029/2005JD006047, 2006.

Estellés, V., Martínez-Lozano, J. A., Utrillas, M. P., and Campanelli, M.: Columnar aerosol properties in Valencia (Spain) by ground-based Sun photometry, J. Geophys. Res., 112, D11201, doi:10.1029/2006JD008167, 2007a.

Estellés, V., Martínez-Lozano, J. A., and Utrillas, M. P.: Influence of air mass history on the columnar aerosol properties at Valencia, Spain, J. Geophys. Res., 112, D15211, doi:10.1029/2007JD008593, 2007b.

Estellés, V., Campanelli, M., Smyth, T., Utrillas, M. P., and Martínez-Lozano, J. A.: AERONET and Euroskyrad (ESR) aerosol optical depth intercomparison on Cimel CE318 and Prede POM radiometers, Remote Sensing of Clouds and the Atmosphere XV, Proc. SPIE, 7827, 7827Y, doi:10.1117/12.865039, 2010.

Estellés, V., Campanelli, M., Smyth, T. J., Utrillas, M. P., and Martínez-Lozano, J. A.: AERONET and ESR sun direct products comparison performed on Cimel CE318 and Prede POM01 solar radiometers, Atmos. Chem. Phys. Discuss., 12, 4341-4371, doi:10.5194/acpd-12-4341-2012, 2012.

Evgenieva, T., Iliev, I., Koleva, N., Sobolewski, P., Pietruczuk, A., Holben, B. N., and Kolev, I.: Optical characteristics of aerosol determined by Cimel, Prede, and Microtops II sun photometers over Belsk (Poland), Proc. SPIE, 7027, 70270V-1, doi: 10.1117/12.822507, 2008.

Gueymard, C. A.: Parameterized transmittance model for direct beam and circumsolar spectral irradiance, Sol. Energy, 71, 3253462001.

Holben, B. N., Eck, T. F., Slutsker, I., Buis, J. P., Setzer, A., Vermote, E., Reagan, J. A., Kaufman, Y., Nakajima, T., Lavenu, F., and Smirnov, A.: AERONET - A federated instrument network and data archive for aerosol characterization, Remote Sens. Environ., 66, 1-16, 1998.

Iqbal, M.: An introduction to solar radiation, Academic Press, London, 390 pp., 1983.

Kasten, F. and Young, A. T.: Revised optical air mass tables and approximation formula, Appl. Optics, 28, 4735-4738, 1989.

Kim, D., Sohn, B., Nakajima, T., Takamura, T., Takemura, T., Choi, B., and Yoon, S.: Aerosol optical properties over east Asia determined from ground-based sky radiation measurements, J. Geophys. Res., 109, D02209, doi:10.1029/2003JD003387, 2004.
Kobayashi, E., Uchiyama, A., Yamazaki, A., and Kudo, R.: Retrieval of aerosol optical properties based on the spheroid model, J. Meteorol. Soc. Jpn., 88, 847-856, doi:10.2151/jmsj.2010-505, 2010.

Michalsky, J. J.: The astronomical almanac's algorithm for approximate solar position (1950-2050), Sol. Energy, 40, 227-235, 1988.

Mishchenko, M. I., Travis, L. D., and Lacis, A. A.: Scattering absorption, and emission of light by small particles, Cambridge Univ. Press, New York, 2002.

Nakajima, T. and Tanaka, M.: Algorithms for radiative intensity calculations in moderately thick atmospheres using a truncation approximation, J. Quant. Spectrosc. Ra., 40, 51-69, 1998.

Nakajima, T., Tanaka, M., and Yamauchi, T.: Retrieval of the optical properties of aerosols from the aureole and extinction data, Appl. Optics, 22, 2951-2959, 1983.

Nakajima, T., Tonna, G., Rao, R., Boi, P., Kaufman, Y., and Holben, B.: Use of sky brightness measurements from ground for remote sensing of particulate polydispersions, Appl. Optics, 35, 26722686, 1996.

Olmo, F. J., Quirantes, A., Alcántara, A., Lyamani, H., and Alados-Arboledas, L.: Preliminary results of a non-spherical aerosol method for the retrieval of the atmospheric aerosol optical properties, J. Quant. Spectros. Ra., 100, 305-314, doi:10.1016/j.jqsrt.2005.11.047, 2006.

OpenCLASTR website: http://www.ccsr.u-tokyo.ac.jp/ clastr/, last access: September 2011.

Ozone Monitoring Instrument website: http://ozoneaq.gsfc.nasa. gov/, last access: October 2011.

Sano, I., Mukai, S., Yamano, M., Takamura, T., Nakajima, T., and Holben, B.: Calibration and validation of retrieved aerosol properties based on AERONET and SKYNET, Adv. Space Res., 32, 2159-2164, 2003.

Segura, S., Estellés, V., Esteve, A. R., Utrillas, M. P., and MartínezLozano, J. A.: Analysis of a severe pollution episode in Valencia (Spain) and its effect on ground PM and BC levels, J. Aerosol Sci., submitted, 2011.

Spencer, J. W.: Fourier series representation of the position of the Sun, Search, 2, 172 pp., 1971.

Tanaka, M., Nakajima, T., and Shiobara, M.: Calibration of a sunphotometer by simultaneous measurements of direct solar and circumsolar radiation, Appl. Optics, 25, 1170-1176, 1986.

Taviro, F.: Determination of the thermal coefficient from Cimel CE318 sunphotometers, Degree project, Universitat de València, Burjassot, Spain, 46 pp., 2011.

Yang, P. and Liou, K. N.: Geometric-optics-integral equation method for light scattering by nonspherical ice crystals, Appl. Optics, 35, 6568-6584, 1996. 